\title{
Output dynamics, flow equilibria and structural change-A prolegomenon to evolutionary macroeconomics
}

\author{
Ulrich Witt • Thomas Brenner
}

Published online: 9 January 2008

(C) Springer-Verlag 2007

\begin{abstract}
In an evolutionary approach to macroeconomics, the market disequilibrium dynamics resulting from structural change need to be properly represented at the aggregate level. As suggested by the late F.A. Hayek, a suitable equilibrium concept required to this end as a frame of reference, is that of a flow equilibrium. The paper explores the corresponding flow dynamics that draw attention to variables not usually considered in macroeconomic theorizing. Using statistical estimates for these new variables for the West German manufacturing sector during the German unification process allows some important new insights on the relationships between structural change and macroeconomic performance.
\end{abstract}

Keywords Macroeconomics · Structural change - Disequilibrium dynamics · Flow equilibrium $\cdot$ Business cycle

JEL classification B $52 \cdot$ D $50 \cdot$ E $00 \cdot$ E $11 \cdot$ E 32

\section{Introduction}

The contours of an evolutionary approach to macroeconomic theory are still far from being clear. An early inquiry by Foster (1987) develops an evolutionary perspective on macroeconomic issues in comparison to Keynesian and post-Keynesian positions. This work was later extended to an econometric approach focusing on the impact of logistic diffusion processes on macroeconomic time series (Foster 1992, Foster and Wild 1999). Another strand of thought is informed by the seminal work of Nelson and Winter (1982, Chap. 4) on innovation driven structural change in industries. The macroeconomic implications of their approach are discussed in terms of disequilibrium growth processes accompanied by productivity changes at the aggregate level, GNP

U. Witt $(\bowtie) \cdot$ T. Brenner

Max Planck Institute of Economics, Kahlaische Str. 10, 07745 Jena, Germany

e-mail: Ulrich.Witt@econ.mpg.de 
growth rate variations, and a catching up and falling behind in international competitiveness (Silverberg and Verspagen 1995, Fagerberg et al. 1997, Fagerberg and Verspagen 2002, Los and Verspagen 2006, Metcalfe et al. 2006).

The agenda of the latter contributions partly overlaps with that of macroeconomic "outof-equilibrium" models that draw much of their inspiration from the neo-Austrian theory of production and growth (Amendola and Gaffard 1998, 2003, Amendola et al. 2005). However, the former literature focuses on how the evolutionary process of structural change results in disequilibria, breaks, and fluctuations reflected in growth accounting at the regional, national, and international levels. The latter writings, in contrast, emphasize how the results of the restructuring of the productive capacity hinge on whether or not inter-temporal complementarities can be upheld in the process of innovation-driven growth. This is the problem of coordination in the economy. It relates to the influence of expectations held by the agents, to the intra-temporal and inter-temporal working of the price mechanism, to the time structure of the flows of goods and services arising from capital accumulation, and to the impact of monetary and fiscal policies.

In the "out-of-equilibrium" approach to evolutionary macroeconomics, a vision of the coordination of aggregate economic activity lives on as it can be found already in Hayek (1941) before the advent of Keynesian macroeconomics, and in Hicks (1973) afterwards. In this vision, the incessant structural change in the economy is seen as an expectation-driven venturing into future production and trade opportunities offered by new technologies. It induces restructurings and disruptions and, hence, a disequilibrium state of the economy. However, as the disequilibrium state is seen as one that elicits coordinating forces, false expectations, prices, and production engagements should sooner or later be corrected. If there were no further profitable restructuring opportunities emerging, aggregate economic activity should therefore be expected to return to an equilibrium state-albeit one that may vary with the technological conditions and the policy regimes chosen.

The association of technological change, capital accumulation, and the restructuring of production with a disequilibrium state of affairs indeed seems uncontroversial in all approaches to evolutionary macroeconomics. Not so, however, the question of what concept of equilibrium, if any, is relevant as a standard of reference. This is an old question that not only concerns definitions, but also, and more fundamentally, the way in which the evolutionary transformation process in the economy can be approached from a macroeconomic point of view. In macroeconomic theorizing, the frame of reference for defining disequilibria is usually the notion of a market equilibrium, i.e. of equality of supply and demand. As will be argued in this paper, on closer inspection of the time structure of aggregate economic activity, a different equilibrium notion shows up. This notion draws attention to dynamic macroeconomic features that, despite the ongoing structural change in the economy, are remarkably robust over time and may therefore play the role of invariance in evolutionary macroeconomics.

The paper proceeds as follows. Section 2 discusses the alternative notions of equilibria relevant for the macroeconomic level. Drawing on a metaphor introduced by Hayek (1981), the notion of an equilibrium in the flow of goods and services over time is contrasted with that of an equilibrium in the aggregate markets for goods and services at a certain point in time, and it is argued that the former fits an evolutionary perspective better. In Section 3 the corresponding macro flow dynamics are explored and are shown to transcend the usual focus on market equilibria. The critical role of 
a velocity variable for the flow equilibrium is pointed out - a variable that is usually not even considered in macroeconomic models. Section 4 looks into the empirical evidence for flow equilibria at the macroeconomic level. Time series data for West Germany are used to estimate the velocity variable whose behavior over time allows to infer whether or not the conditions for a flow equilibrium are met for the time period under consideration. Section 5 offers conclusions.

\section{What notion of equilibrium?}

The very notion of a dis-equilibrium can be claimed to make sense only with reference to a state of equilibrium. This does not necessarily mean, however, that equilibrium states are indeed relevant for the trajectories of macroeconomic variables. A trajectory in which no equilibrium point or orbit occurs is sufficiently characterized as a disequilibrium (or "out-of-equilibrium," Amendola and Gaffard 1998) process. ${ }^{1}$ Furthermore, in the cases in which an equilibrium concept is, in fact, relevant, it does not necessarily have to refer to equilibria in markets, as is usually the case in macroeconomic theories. Most of these focus on (simultaneous) equilibria in the aggregate markets for goods, money, and the factors of production (or on equilibrium growth paths characterized by equal growth rates for all relevant variables). If supply were indeed equal to demand in all markets, this would be a state of perfect market coordination. While such a state is a precondition for an efficient resource allocation at the disaggregate level and, ultimately, for the concept of a general equilibrium in the economy, it is unlikely to occur in reality.

This is true, in particular, in the presence of structural change. Characteristic of competitive, capitalist economies and their growth, structural change necessarily implies disruptions for many market participants and elements of de-coordination or "creative destruction," as Schumpeter (1942) put it. Though perfect market coordination cannot be expected to prevail under such conditions, a considerable degree of coordination of production and exchange can still be observed. The idea of market coordination therefore seems to call here for a conceptualization that is not confined to market equilibrium states. An equilibrium notion corresponding to such a broader view of the coordinating problem has been suggested by Hayek (1981). This contrasts remarkably with Hayek's earlier contributions to business cycle theory, monetary issues, and the time structure of investment and capital accumulation that had gained him a reputation as a leading economic theorist and that are all firmly molded in a market equilibrium analysis. For understanding the broader notion of equilibrium, it is worth noting the reasons that induced Hayek to dismiss the narrower one.

By the end of the 1940s, Hayek had for several reasons turned his back on issues related to aggregate economic activity (McCormick 1992) and started working on social philosophy instead. The outgrowth of this work was his evolutionary theory of the spontaneously emerging "extended order of the markets" (Hayek 1988). The theory holds that individual knowledge is incomplete and hypothetical. As a

\footnotetext{
${ }^{1}$ This is, e.g., the case for chaotic time series. See the discussion in Baumol and Benhabib (1989) and Ruelle (1991).
} 
consequence, there is room for experimentation, discoveries, and surprises in the economy (Hayek 1978). However, through their learning via market interactions, agents are able to realize ordered forms of production and trade. In Hayek's reflections on what "the twin idea of a spontaneous order and societal evolution" implies for the cultural, legal, and political basis of market economies, the 'macroeconomic' topics that interested him earlier no longer played a particular role. If this had not been the case, the strong equilibrium focus of the earlier writings would have been difficult to reconcile with the evolutionary views he was about to elaborate.

Hayek (1981) addressed this problem in a rather late and little noticed lecture. ${ }^{2}$ To solve it he introduced the metaphor of a river system by which he intended to capture crucial features of the flow of goods and services in an economy: "... conceive of the whole process of production as a continuous stream or flow which at its mouth yields a continuous output, emerging after having passed through various transformations since the first resources had been applied. At any one moment a great number of such streams, or rather complex ramified river systems, will be proceeding concurrently, each a little more advanced than the next one. The finished products of all these streams will emerge at more or less distant future dates" (ibid. p.3). In view of the complex time structure of the flows alluded to in the metaphor, it is by no means clear what role an equilibrium concept can play.

Accordingly, Hayek writes: "It is very tempting to describe as an 'equilibrium' an ideal state of affairs in which the intentions of all participants precisely match and where each will find a partner willing to enter into the intended transaction. But for all capitalistic production there must exist a considerable interval of time between the beginning of a process and its various later stages which makes the achievement of such an equilibrium impossible.... Even an apparent momentary state of balance in which everybody succeeds in selling or buying what he intended, may be inherently unrepeatable, irrespective of any change in the internal data, because some of the constituents of the stream will be the results of past conditions which have changed long ago" (ibid. p.8).

Obviously, using the metaphor of the flow for the evolving aggregate economic process, the price system and, even more so, the notion of a market equilibrium lose much of their significance for understanding how, and to what extent, economic activities are coordinated. There is no basis for assuming a uniform price for the goods and services. But, even in the presence of massive structural change, agents can be assumed to be aware of the fact that the prices they can charge for their offers have an upper bound where demand becomes zero. Moreover, there is a lower bound where the unit costs of making an offer - usually hinging on earlier investment decisionscan no longer be covered. Search activities and competition tend to bring down over time the upper bound and learning and technological progress the lower bound.

\footnotetext{
${ }^{2}$ The lecture was given in 1981 at the London School of Economics;"...to the day exactly 50 years after I delivered from the same platform the first of four lectures that led to my appointment to a professorship at this school", Hayek starts. Time and location signal that Hayek himself considered the lecture an occasion on which to present second thoughts about his earlier views. The English manuscript of the lecture was never published. It has, however, been translated and published in German (Hayek 1984). The authors are grateful to Dr. Claudia Loy, who translated the manuscript, for making available a copy of her private exemplar, cited here as Hayek (1981).
} 
As long as the agents' margin between the upper and lower bounds does not persistently turn negative, and as long as agents adjust prices and quantities properly, they can stay in business. Losses and overdrawing of budgets alert them of the need to review their costs and prices, to engage in developing improved products and to invest in new technologies. Agents who nonetheless fail to uphold and profit from a nonnegative margin are forced out of business and their resources are laid idle. In this sense, there are indeed coordinating incentives mediated by the price mechanism that keep up a viable degree of coordination in the economy. It is less than perfect because of losses and failures, mis-allocations and idle resources that may occur and because of profit opportunities and windfall gains. Even if all businesses could survive under the viable degree of coordination in the markets, the state of a general equilibrium (corresponding to a unique equilibrium price vector) would therefore not be attained.

What follows for the macroeconomic variables from these dynamic features of a less than perfect market coordination process - and what follows for the equilibrium notion? Amendola and Gaffard (1998, Chap.1) rightly make the following point. If the extent of coordination is no more than a viable one as just described, both the inter-temporal and the intra-temporal complementarity of aggregate variables is no longer guaranteed. This concerns consumption, saving, and investment on the one hand, and employment opportunities, factor supply, and factor income on the other. Deviations from the complementarity conditions upstream are likely to affect the flow of goods and services coming out of the production process downstream, both in its growth potential over time and in its business cycle patterns. This is the immediate consequence of giving up the fiction of perfect coordination. A challenge that remains is to demonstrate that, despite its fluctuations over time, the observable stream of goods and services and the corresponding macroeconomic variables still express a significant degree of coordination. Hayek's metaphor suggests a way to demonstrate this — and, by the same token, puts forth a different equilibrium notion.

In spite of the fluctuations in aggregate output and the likely lack of intertemporal complementarities in producing it, one form of complementarity may still be sustained in the processing of goods and services. This is, to stick to Hayek's metaphor, the balance between the influx upstream and the outflow at the mouth of the stream. The condition relevant for this kind of intra-temporal and inter-temporal complementarity can be stated by means of the concept of a flow equilibrium.

Definition A flow equilibrium results if influx and outflow in a flow system over a given period of time are balanced in such a way that a constant relation between the system's capacity and its throughput is stabilized (steady flow).

Obviously, this is an inherently dynamic equilibrium concept which, when applied to the flow of goods and services, implies a much weaker condition for the extent of coordination in the economy than the concept of a general equilibrium in all markets does. If the concept of a flow equilibrium is used to test empirically the presence of a viable coordination in aggregate economic time series, two problems arise. The first is to find adequate economic variables by which influx and outflow can be measured. The second problem is to determine theoretically by what kind of economic processes the influx is translated into an outflow. These two problems will be discussed in the next section. 


\section{Macro flow dynamics and the neglected velocity variable}

The extent of intra-temporal and inter-temporal coordination in the flow of goods and services can best be grasped when attention is redirected from market exchange activities to the time structure of the production process on which the timing of the market transactions rests. Imagine the production sector of the economy as a huge system of servicing channels in which arriving orders (and - as will be tacitly assumed-future offers planned by the producers) are processed by passing through various processing steps and/or processing units. Accordingly, the orders received in a given period of time $t, r(t)$, can be taken to represent the influx variable in the flow interpretation. The outflow variable is the output produced in a period $t, q(t)$, that results from the earlier orders. The time lag between an influx turning into an outflow hinges on the kind of the goods and services, the technology by which they are produced, and other, usually industry-specific, features. Foremost, however, it depends on the average number of processing units required to be passed through under the given organizational and technical conditions and the potentially varying, average speed $v(t)$ with which the processing advances under the given capacity constraints per unit of time.

The average number of processing units and the other industry specific features can be treated as technological parameters that are independent of the production capacity. In contrast, the time that is needed on average for processing orders in the economy is a variable that depends on the ratio between the total orders in process in a given period of time $t, R(t)$, and the production capacity available at that time. $R(t)$ is defined more precisely as the sum of $r(t)$ and the orders received previous to that have not yet been worked off, i.e.

$$
R(t)=r(t)+\sum_{n=1}^{t-1} r(n)-q(n) .
$$

A straight forward hypothesis can be stated as follows.

Assumption 1 The average order processing speed $v(t)$ is constant as long as there is no bottleneck in the processing (production) capacity of the economy. Once $R(t)$ exceeds the existing processing capacity at a critical value $R^{*}$, however, $v(t)$ starts to decrease.

Note that the reaction of the processing speed to the servicing or production capacity becoming jammed is a technical feature that cannot be influenced by price adjustments. Prices may, of course, vary when the orders in process grow and may thus affect the order activities. But even this is not self-evident as is sometimes presupposed within a market equilibrium framework.

If economic agents have incomplete, fallible knowledge, it is quite natural for them to fail to foresee, or to account for, the actual volume of demand in the future when they make their necessarily speculative investment and saving decisions on the basis of the price information available today. The consequence is a lack of intertemporal complementary of accumulation, production, and consumption activities. At the end of the pipe, this may result in a change in spot prices that can clear the markets, but it cannot prevent the failure to achieve inter-temporal market equilibria. Moreover, even market clearing spot prices do not ensure an intra-temporal complementarity between orders given on the one side and the existing production 
capacity on the other. It is because of this fact that the average processing speed in the economy varies in the asymmetric way stated in Assumption 1.

A similar asymmetry holds with respect to the conditions of a flow equilibrium. A lasting slump in the order volume (the influx), which results in excess capacity, leads to a lasting reduction in deliveries (the outflow) later. However, because of the steady throughput after the reduction, the economy is still in a flow equilibrium, albeit at a lower throughput level. In contrast, a lasting order volume in excess of $R^{*}$ tends to pile up over time. This is an unsteady flow condition. By Assumption 1, $v(t)$ is constant in the first case and decreases in the second case. Hence it follows from the above definition of a flow equilibrium and by Assumption 1 that

Proposition 1 A constant processing speed $v(t)$ is a necessary condition for a flow equilibrium in the economic production system.

The simple logic of the flow metaphor thus suggests a functional relationship between aggregate output $q(t)$ per period of time $t$ as the dependent variable and a few independent variables not usually considered in macroeconomic theorizing. The average order processing speed $v(t)$, for instance, is neglected even in dynamic macroeconomic models, although it represents a constitutive aspect of the time dependence of the aggregate production process. Another variable to which attention is drawn is the capacity of the economy's servicing or production system, a variable that is difficult to measure. However, using the flow analogy, a way can be found to relate it to the orders in process, $R(t)$, a variable that can more easily be measured.

In certain fluid systems, the throughput, measured by the number of particles leaving a certain segment of the flow per period of time, can be approximated by the density of the particles in the flow segment times their average flow velocity (see e.g. Helbig 1995). Here, the density indirectly reflects a capacity measure. Analogously, one can assume for the flow representation of macroeconomic dynamics:

Assumption $2 q(t)$ results from the orders in process $R(t)$ in a given period of time $\mathrm{t}$ multiplied by the average speed $v(t)$ with which they are processed. ${ }^{3}$

Thus, we can write

$$
q(t)=v(t) \times R(t)
$$

As long as $v(t)=$ const., $q(t)$ varies proportionally with $R(t)$ and, by Proposition 1 , the condition for a flow equilibrium is satisfied. Given the functional relationship stated in Assumption 2 a further proposition can be deduced.

Proposition 2 For $R(t)>R^{*}, q(t)$ increases less than proportionally with $R(t)$, implying that Eq. 2 becomes non-linear.

\footnotetext{
${ }^{3}$ The dimensions are output in money value per period, orders in money value per number of processing units, and number of processing units passed per period, respectively. The average processing speed $v(t)$ is treated as a constant in t. Note that $R(t)$ captures all orders currently in the system, independently of how far they have gotten in their processing.
} 
Proposition 2 follows directly from Assumption 1 stating that $v(t)$ decreases with growing $R(t)>R^{*}$.

This result points to a macroeconomic dynamic in which even the weak condition of a flow equilibrium is violated. To put it differently, the less than perfect degree of coordination no longer ensures a steady macro flow in the economy. The consequence of the lacking inter-temporal and intra-temporal complementarities are, in this case, the market shortages that are induced by a booming order activity. Increasingly growing order backlogs lead to bottlenecks at some places that begin to induce delays at other places. Firms start to have troubles with finishing projects and delivering on time. Tight schedules prevailing everywhere, substitutes may not quickly be available. The average processing speed can thus be significantly reduced until an expansion of the production capacity (resulting from revised investment decisions becoming effective) eventually allows a reduction of order backlogs. Lost time can be made up so that the average processing speed goes up again.

Once more an asymmetry turns up here, though one with more dramatic macroeconomic implications. As has been shown elsewhere (Witt and Sun 2002), once the critical range $R(t)>R^{*}$ is reached-i.e. for a non-linear specification of Eq. 2 - under certain conditions, shortage induced cyclical variations of $q(t)$ can occur. Note that this is not possible as long as $R(t) \leq R^{*}$-i.e. for a linear specification of Eq. 2. (Cyclical variations in output, if they occur in that range, can of course have other causes.) An intra-temporal lack of complementarity between aggregate output and income, resulting in an effective demand failure that figures so prominently in Keynesian macroeconomics (see Leijonhufvud 1981), would be tantamount to a slump in the order volume and a later reduction in output. It would not, however, affect the processing speed and, hence, the flow equilibrium.

It is not clear, though, whether a situation with resources laid idle - unemployment of labor and capital — would indeed persist for long in the presence of an incessant process of structural change. Under such conditions, an inter-temporal complementarity between consumption expenditures and accumulation rates that would preserve a situation of effective demand failure is not very likely. One reason is that the two variables vary at different, and not perfectly coordinated, time scales. A further reason is that investment decisions in the past can affect not only the production capacity but also the order volume today in a way that is largely independent of the current income. To put it in Hayek's metaphorical terms: “... the volume of the stream will tend to swell or shrink in some degree because final demand, and demand for primary factors, will change at different rates, and at times even in opposite directions. The conventional picture on which the whole of Keynesian analysis is based which represents the connection between final demand and employment as analogous to the relation between the suction applied at one end of the pipe and its intake at the other end, is thus very misleading. Between the two lies an elastic or variable reservoir" (Hayek 1981, p. 4).

\section{Macroeconomic dynamics and the flow equilibrium: an empirical investigation}

To assess the empirical relevance of the analytical tools presented in the previous section, an attempt can be made to estimate the variation of the average order 黑 Springer 
Fig. 1 Monthly variations of aggregate output and orders in process (West German Manufacturing Sector). source: German Federal Statistical Office and own calculations

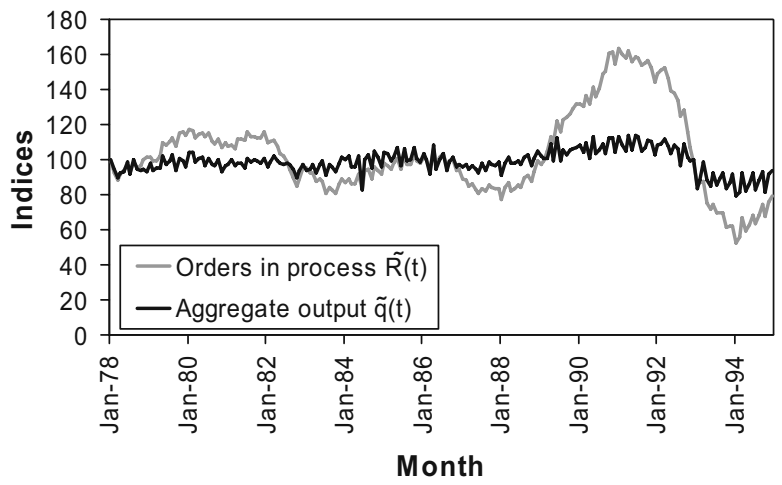

processing speed on the basis of the time series of the macroeconomic variables in Eq. 2. If, in estimating the parameters of Eq. 2 for a time series over an extended period, a linear specification turns out to be statistically significant, the average processing speed is a constant. By Proposition 1 this would imply an economic situation during the chosen period of time which is characterized by a flow equilibrium. If, in contrast, the estimation supports a non-linear specification of Eq. 2 , then, by Proposition 2, the $q(t) / R(t)$ ratio and, hence, $v(t)$ decrease for growing $R(t)$ values. In this case the flow equilibrium condition would not be satisfied.

In order to carry out this test, we use the monthly turnover data published by the German Federal Statistical Office for the West German manufacturing sector as the basis for measuring aggregate output. The time period chosen is January 1978 to December 1994. The orders in process as defined in Eq. 1 above are measured on the basis of the monthly data for the index of the orders $\tilde{r}^{\sim}(t)$ received by the manufacturing sector per month. This index time series has been compiled for West Germany by the German Federal Statistical Office only for the years 1978 to 1994. For measuring aggregate output over the same period of time, the monthly data for the index of aggregate output $q^{\sim}(t)$ of the West German manufacturing sector are used as published by the German Federal Statistical Office. ${ }^{4}$ The indices have been transformed to eliminate seasonal variations and to remove the exponential trend from each of the time series. Finally, both indices have been normalized to a value $q^{\sim}\left(t=\right.$ January 1978) $=R^{\sim}(t=$ January 1978 $)=100$.

The time series of the index values $q^{\sim}(t)$ and $R^{\sim}(t)$ thus calculated are displayed in Fig. 1. The soaring growth of $R^{\sim}(t)$ in the period 1989-1991 reflects the effect of the German unification. The West German economy was not prepared for this extraordinary expansion in orders, as the modest increase in $q^{\sim}(t)$ over this period of time shows. The production capacity could simply not be adjusted rapidly enough. The equally dramatic subsequent decline of $R^{\sim}(t)$ indicates that the order expansion was indeed a singular event that did not create a lasting rise of the output level.

\footnotetext{
${ }^{4}$ Since both $r^{\sim}(t)$ and $q^{\sim}(t)$ are in index form, identical value for the two variables do not necessarily imply that the underlying absolute money values are identical. For the period 1978 to 1984, the German Federal Statistical Office has also calculated on a monthly basis an index for the money value of the stock of orders corresponding to $R(t)-r(t)$. This time series has been used here for calibrating $\sim \sim(t)$ by means of the corresponding $q^{\sim}(t)$-values.
} 


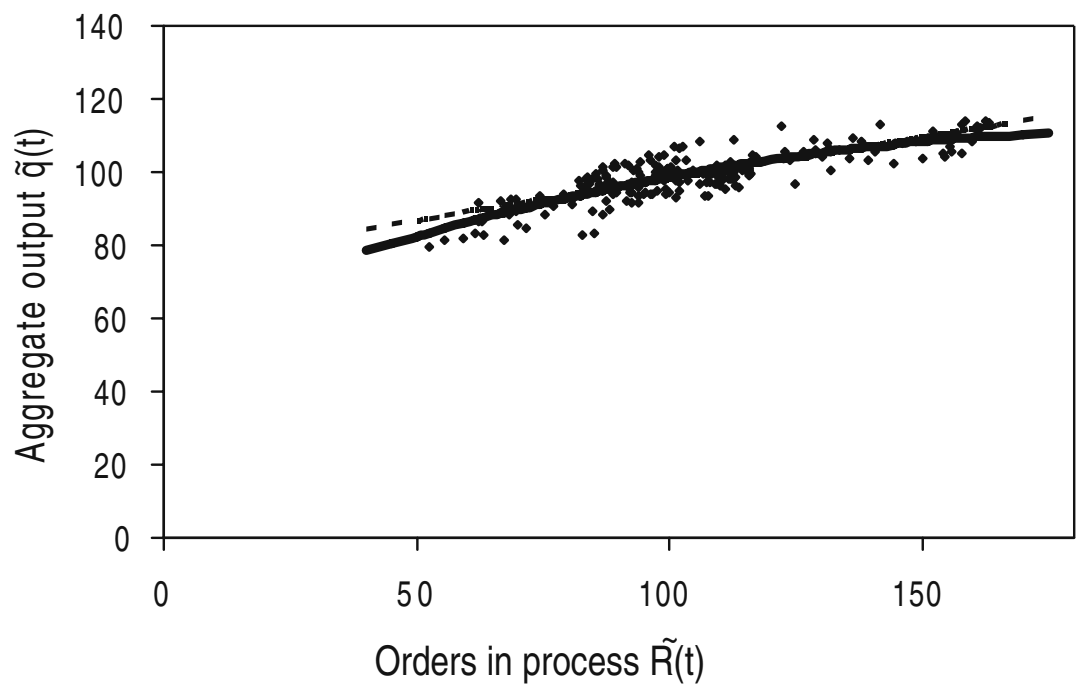

Fig. 2 Monthly aggregate output values regressed on orders in process

The question of whether or not the average processing speed in the West German economy was constant over the period 1978-1994 and, thus, whether or not the condition for a flow equilibrium was satisfied, can be answered by using the empirical data to estimate the relationship between $q^{\sim}(t)$ and $R^{\sim}(t)$. We test the quadratic form

$$
q^{\sim}(t)=\alpha+\beta R^{\sim}(t)+\gamma\left[R^{\sim}(t)\right]^{2}
$$

that can be derived from Eq. $2 .^{5}$ Figure 2 presents the scatter diagram in which the $q^{\sim}$ values for each month are depicted against the corresponding $R^{\sim}$-values. Applying a standard OLS regression on Eq. 3, it turns out that the coefficient $\gamma$ for the quadratic term is highly significant (see Table 1). The hypothesis that the average processing speed is constant in $R^{\sim}(t)$, i.e. the hypothesis of a linear relationship, can therefore be rejected.

The empirical findings for the manufacturing sector in West Germany provide evidence for the fact that, during the period 1978-1994, the economy was not in a flow equilibrium. Increases in the orders in process jammed the manufacturing sector, causing statistically significant delays in the average order processing speed. The singular order boom accompanying the German unification certainly contributed to this result, but may not have been the only reason.

At a deeper level, this finding points to the limitations of the price mechanism for coordinating the economic activities both inter-temporally and intra-temporally. It is not able to prevent or immediately control strong variations in orders received over time, so that the production capacity of the economy, determined by earlier

\footnotetext{
${ }^{5}$ Since the indices $q^{\sim}(t)$ and $R^{\sim}(t)$ are scalar transformations of the absolute values, their ratio is equivalent to $q(t) / R(t)=v(t)$ in Eq. 1 .

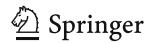


Table 1. Regression results for Eq. 3

$R^{2}=0.686$

\begin{tabular}{lll}
\hline Parameters & Estimates & Significance \\
\hline$\alpha$ & 59.970 & 0.000 \\
$\beta$ & 0.516 & 0.000 \\
$\gamma$ & -0.001297 & 0.000 \\
\hline
\end{tabular}

accumulation and investment decisions, can become strained or even exhausted. The missing coordinating power casts doubts on the usefulness of the strong reliance in macroeconomic theorizing on the concept of market equilibria, as these may not be as significant for the dynamics of macroeconomic variables, as is often implicitly assumed. Moreover, the evidence found for the violation of the flow equilibrium condition raises additional questions regarding the explanation of the cyclical variations in growth of aggregate output in the manufacturing sector as shown in Fig. 1. For a non-linear shape of the graph of Eq. 2 it has been proved by Witt and Sun (2002) that endogenously emerging cyclical variations in aggregate output are possible. With the statistically significant quadratic term in Eq. 3 one cannot exclude the possibility that the order processing dynamics also contributes to business cycle fluctuations in the economy.

\section{Conclusions}

A problem to be tackled by an evolutionary approach to macroeconomics is to represent the disequilibrium dynamics in the markets resulting from the incessant structural change at the aggregate level. To this end, some notion of an equilibrium must be chosen as a frame of reference. In this paper, the concept of a flow equilibrium has been proposed as a solution to the problem. This concept only requires a balance in the flow of goods and services over time, but not necessarily an equilibrium in the aggregate markets at every point in time. Hence, it is a concept that fits the conditions of a less than perfect inter-temporal and intra-temporal coordination of the economy via the markets, as it is needed to account for the impact of structural change and adjustments. The concept has been illustrated by means of a metaphor suggested by the late F.A. Hayek. His motivation for using the metaphor highlights a development in his own work away from narrow market equilibrium notions to a broader, evolutionary view.

The macro flow dynamics corresponding to the notion of a flow equilibrium have been theoretically outlined. As it turned out, an approach like this draws attention to variables not usually considered in macroeconomic theorizing. These variables relate to the volume of orders, the order processing (production) capacity, and the order processing speed. In a flow perspective, these are decisive for the output dynamics. By a simple specification of the relationships between them, it has been possible to derive two core hypotheses. One concerns the necessary condition for a flow equilibrium, the other focuses on the critical behavior of the velocity variable.

Finally, the paper explored the empirical evidence for flow equilibria occurring at the macroeconomic level. On the basis of time series data for the West German manufacturing sector 1978 - 1994, the velocity variable has been estimated. It has 
been shown that the condition for a flow equilibrium was not satisfied for the time period under consideration. From earlier work (Witt and Sun 2002) it is known that, in this case, cyclical variations of aggregate output can occur. The empirical findings therefore also provide evidence for the possibility that flow equilibria play an important role for the relationships between structural change and business cycle phenomena.

\section{References}

Amendola M, Gaffard J-L (1998) Out of equilibrium. Clarendon, Oxford

Amendola M, Gaffard J-L (2003) Persistent unemployment and co-ordination issues: an evolutionary perspective. J Evol Econ 13:1-27

Amendola M, Gaffard J-L, Saraceno F (2005) Technical progress, accumulation of capital and financial constraints: is the productivity paradox really a paradox. Struct Chang Econ Dyn 16:243-261

Baumol WJ, Benhabib J (1989) Chaos: significance, mechanisms, and economic applications. J Econ Perspect 3:77-105

Fagerberg J, Verspagen B (2002) Technology-gaps, innovation-diffusion and transformation: an evolutionary interpretation. Res Policy 31:1291-1304

Fagerberg J, Verspagen B, Caniels M (1997) Technology growth and unemployment across European regions. Reg Stud 31:457-466

Foster J (1987) Evolutionary macroeconomics. Allen \& Unwin, London

Foster J (1992) The determination of the sterling M 3, 1963-88: an evolutionary macroeconomic approach. Econ J 02:481-496

Foster J, Wild Ph (1999) Econometric modelling in the presence of evolutionary change. Camb J Econ 23:749-770

Hayek FA (1941) The pure theory of capital. Routledge, London

Hayek FA (1978) Competition as a discovery procedure. In: Hayek FA (ed) New studies in philosophy, politics, economics and the history of ideas. Routledge, London, pp 179-190

Hayek FA (1981) The flow of goods and services. Lecture at L.S.E., January 27, 1981

Hayek FA (1984) Der Strom der Güter und Leistungen. Walter-Eucken-Institut, Vorträge und Aufsätze No. 63, Tübingen: Mohr-Siebeck

Hayek FA (1988) In: Bartely WW III (ed) The fatal conceit: the errors of socialism. Routledge, London

Helbig D (1995) Improved fluid-dynamic model for vehicular traffic. Phys Rev, E 51:3164-3169

Hicks JR (1973) Capital and time. Clarendon, Oxford

Leijonhufvud A (1981) Information and coordination-essays in macroeconomic theory. Oxford University Press, Oxford

Los B, Verspagen B (2006) The evolution of productivity gaps and specialization patterns. Metroeconomica 57:464-493

McCormick BJ (1992) Hayek and the Keynesian avalanche. Harvester Wheatsheaf, New York

Metcalfe JS, Foster J, Ramlogan R (2006) Adaptive economic growth. Camb J Econ 30:7-32

Nelson RR, Winter SG (1982) An evolutionary theory of economic change. Harvard University Press, Cambridge, Mass

Ruelle D (1991) Chaotic evolution and strange attractors. Cambridge University Press, Cambridge

Schumpeter JA (1942) Capitalism, socialism and democracy. Harper, New York

Silverberg G, Verspagen B (1995) Long term cyclical variations of catching up and falling behind-an evolutionary model. J Evol Econ 5:209-227

Witt U, Sun G-Z (2002) Myopic behavior and cycles in aggregate output. Jahrbuecher fuer Nationaloekonomie und Statistik 222:366-376 